\title{
An Experimental Study on Strength Properties of Concrete When Cement Is Partially Replaced With Sugar-Cane Bagasse Ash
}

\author{
G. Sireesha ${ }^{1}$, M. Kanta Rao ${ }^{2}$, P. Kanta Rao ${ }^{3}$ \\ ${ }^{1}$ Post graduate student, Department of Civil Engineering, V.R. Siddhartha Engineering College, Vijayawada- \\ 520007 \\ ${ }^{2}$ Sr.Assistant Professor, Department of Civil Engineering, V.R. Siddhartha Engineering college, Vijayawada- \\ 520007 \\ ${ }^{3}$ Assistant Manager, R \& D Department, K.C.P Sugar and Industries Corporation LTD, Vuyyuru, Vijayawada- \\ 521165
}

\begin{abstract}
Ordinary Portland cement is recognized as major construction material throughout the world. Cement is responsible for about $5 \%-8 \%$ of global $\mathrm{Co}_{2}$ emissions. Therefore the utilization of industrial waste has been increased which is environment friendly. In this paper an attempt has been made to utilize sugarcane bagasse ash (S.C.B.A) a residue from sugar industry as a supplementary cement replacement material.

The present study investigates with the strength and durability properties of the concrete when the cement is replaced with S.C.B.A in different proportions. In the first stage the S.C.B.A (B.A.1) is partially replaced in the percentages of 0 to $40 \%$ in increasing steps of $5 \%$. Further in the second stage the S.C.B.A (B.A.2) is heated up to $850^{\circ} \mathrm{c}$ for about 8 hours in a muffle furnace and is replaced in the percentages of 0 to $40 \%$ in increasing steps of 5\%. Cubes, Cylinders and Beams are casted and tests are conducted and compressive strength, split tensile strength and flexural strength obtained for both the conditions.
\end{abstract}

Keywords: Compressive strength, Flexural strength, Split tensile strength, Sugarcane bagasse ash.

\section{Introduction}

Sugarcane bagasse is a fibrous residue after crushing and juice extraction from sugarcane. This bagasse is used as a biomass fuel in the boilers to generate power in the sugar industry. The ash which was obtained from the boiler is a major waste product. It contains high volume of $\mathbf{s i o}_{2}$. Therefore it is classified as a good pozzolanic material

S.C.B.A can be used as a supplementary cementitious material due to its pozzolanic property. In the previous studies it was stated that bagasse ash can replace cement up to $10 \%$ only, after that the compressive strength is going to be get reduced.

In the present study the ash which was obtained from the boiler is partially replaced in the ratio of $0 \%$ to $40 \%$ by weight of cement. And the ash is again heated up to $850^{\circ} \mathrm{c}$ for about 8 hours and is partially replaced in the ratio of $0 \%$ to $40 \%$ and comparison is made between the obtained results.

\section{Materials}

2.1. Cement: The ordinary Portland cement of 53 grade is used. The specific gravity of the cement used is 3.15

2.2. Fine aggregate: Locally available river bed sand is used as fine aggregate. The sand particles should also pack to give minimum void ratio, higher the voids content leads to requirement of more mixing water. The sand used in this comes under zone II. The specific gravity of sand is 2.74 and fineness modulus of 2.86 .

2.3. Coarse aggregate: The crushed aggregates used were $20 \mathrm{~mm}$ nominal maximum size and minimum size of $12 \mathrm{~mm}$. The specific gravity of the coarse aggregate used is 2.63 .

2.4. Sugarcane bagasse ash: In this study the bagasse ash used is collected from K.C.P Sugar and Industries Corporation LTD, Vuyyuru, Vijayawada. The fineness of the bagasse ash is $1709.86 \mathrm{~cm}^{2} / \mathrm{g}$ obtained from Blaine's fineness apparatus. The specific gravity obtained is 2.16 
Table 1 Chemical composition of bagasse ash

\begin{tabular}{|c|c|}
\hline Name of the oxide & Composition (\%) \\
\hline $\mathrm{SiO}_{2}$ & 71.0 \\
\hline $\mathrm{A}_{2} \mathrm{O}_{3}$ & 4.69 \\
\hline $\mathrm{Fe}_{2} \mathrm{O}_{3}$ & 2.0 \\
\hline $\mathrm{CaO}$ & 3.4 \\
\hline $\mathrm{MgO}$ & 0.90 \\
\hline $\mathrm{SO}_{3}$ & 0.20 \\
\hline $\mathrm{K}_{2} \mathrm{O}$ & 2.51 \\
\hline
\end{tabular}

\section{Methodology}

3.1. Mix design: According to I.S 10262:2009 the mix design is done for M25 grade of concrete to attain medium workability, for water-cement ratio of 0.44 . The mix proportion obtained is 1:1.6:3.2.

3.2. Experimental work: The S.C.B.A collected from the sugar industry (B.A.1) is directly used as a cement replacement material. The ash is replaced in the percentages of $0,5,10,1520,25,30,35$ and 40 by the weight of cement

Further, the ash which was collected from the sugar industry is again heated up to $850^{\circ} \mathrm{c}$ in muffle furnace for about 8 hours (B.A.2). The residue after the heat treatment is collected cooled and then replaced in the percentages of $0,5,10,15,20,25,30,35$ and 40 by the weight of cement in concrete.

3.3. Test procedure: The concrete is casted into cube moulds of size $150 \mathrm{~mm} \times 150 \mathrm{~mm} \times 150 \mathrm{~mm}$, beam moulds of size 100X100X500 mm and cylindrical moulds of $300 \mathrm{~mm}$ height x $150 \mathrm{~mm}$ dia. After 24 hours the specimens are submerged in water for 28 days. Tests are conducted after 28 days of curing.

\section{Results And Discussion}

The tests are performed by replacing cement with S.C.B.A (B.A1) and S.C.B.A which was heated up to $850^{\circ} \mathrm{c}$ for about 8 hours (B.A2) and comparison is made between the results of B.A1 and B.A2. Table 2 represents the Compressive, Tensile and Flexural strength obtained for B.A1 and B.A 2 for various proportions. Fig1, Fig2 and Fig3 show the Compressive, tensile and flexural strength of B.A 1 and B.A 2 for various proportions.

Table 2 Comparison $b / w$ the results of B.A.1 and B.A.2

\begin{tabular}{|c|c|c|c|c|c|c|}
\hline $\begin{array}{c}\text { Percentage } \\
\text { replacement of } \\
\text { cement by ash }\end{array}$ & \multicolumn{2}{|c|}{$\begin{array}{c}\text { Compressive strength } \\
\text { @ 28 days } \\
\left(\mathrm{N} / \mathrm{mm}^{2}\right)\end{array}$} & \multicolumn{2}{c|}{$\begin{array}{c}\text { Tensile strength } \\
\text { @ 28 days } \\
\left(\mathrm{N} / \mathrm{mm}^{2}\right)\end{array}$} & \multicolumn{2}{c|}{$\begin{array}{c}\text { Flexural strength } \\
\text { @ 28 days } \\
\left(\mathrm{N} / \mathrm{mm}^{2}\right)\end{array}$} \\
\cline { 2 - 8 } & B.A.1 & B.A.2 & B.A.1 & B.A.2 & B.A.1 & B.A.2 \\
\hline 0 & 34.67 & 34.67 & 2.96 & 2.96 & 5 & 5 \\
\hline 5 & 46.89 & 45.33 & 3.45 & 3.24 & 7.25 & 6.37 \\
\hline 10 & 37.74 & 47.41 & 3.18 & 3.38 & 6.25 & 7 \\
\hline 15 & 32.11 & 49.92 & 3.17 & 3.6 & 5.37 & 7.25 \\
\hline 20 & 26.67 & 46.22 & 3.11 & 4.315 & 4.35 & 7.37 \\
\hline 25 & 22.89 & 44.74 & 2.91 & 4.38 & 3.91 & 7.5 \\
\hline 30 & 19.24 & 41.48 & 2.76 & 3.96 & 3.25 & 8.5 \\
\hline 35 & 17.66 & 38.67 & 2.64 & 3.6 & 3.00 & 7.3 \\
\hline 40 & 17.00 & 36 & 2.55 & 3.29 & 2.79 & 4.08 \\
\hline
\end{tabular}




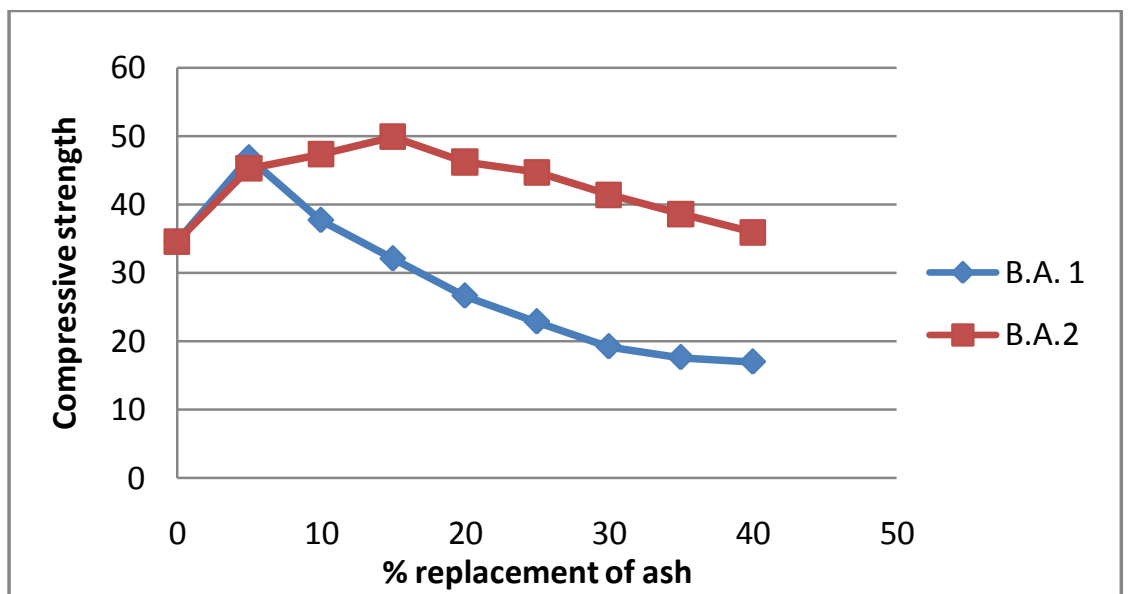

Figure 1 Compressive strength of concrete in $\mathrm{N} / \mathrm{mm}^{2} @ 28$ days

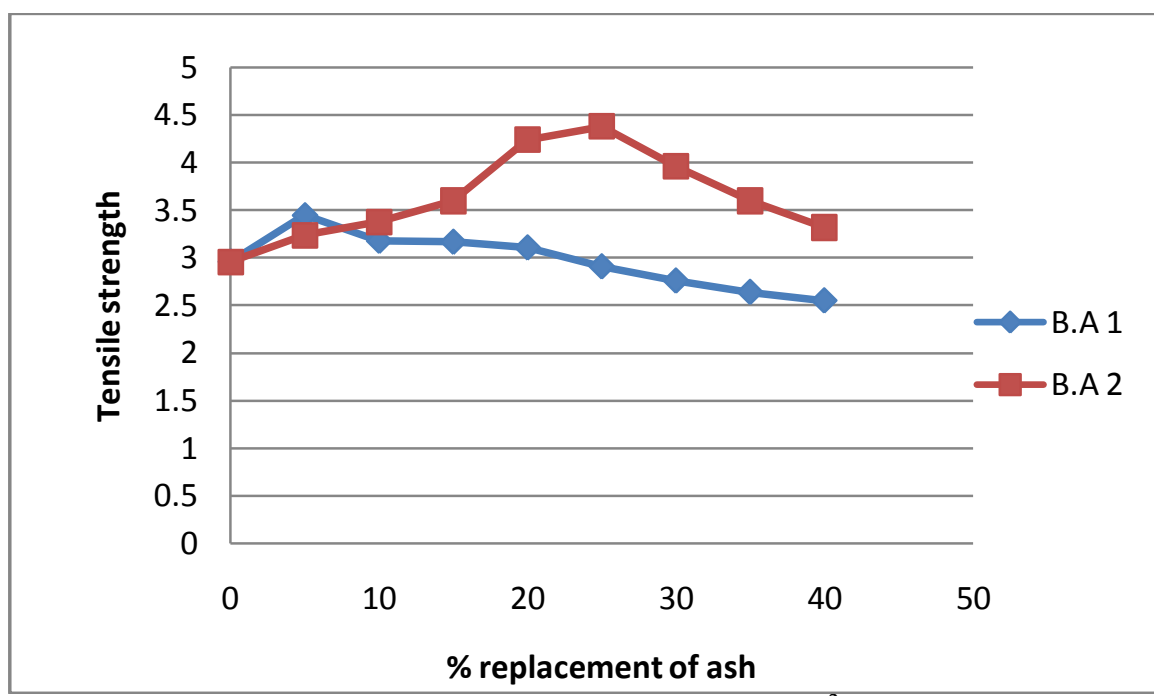

Figure 2. Tensile strength of concrete in $\mathrm{N} / \mathrm{mm}^{2} @ 28$ days

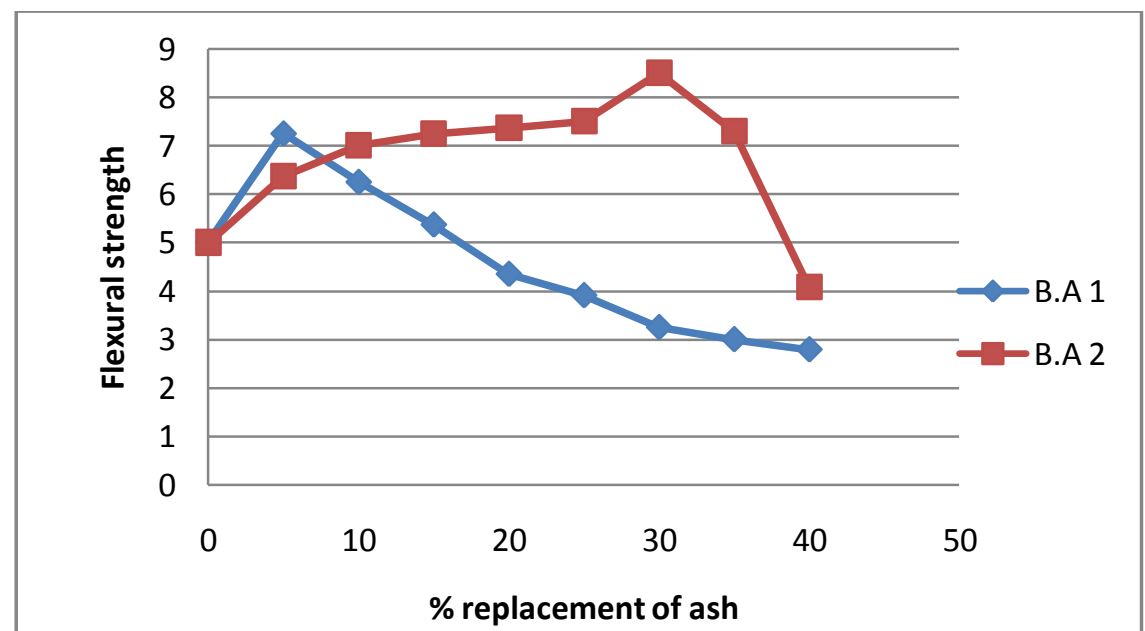

Figure 3 Flexural strength of concrete in $\mathrm{N} / \mathrm{mm}^{2} @ 28$ days

\section{Conclusion}

Based on this study it can be concluded that

[1] The maximum compressive, split tensile, flexural strengths are obtained at $5 \%$ when the cement is replaced with B.A 1.

[2] The maximum compressive strength is obtained at $15 \%$, tensile strength is obtained at $20 \%$ and flexural strength is obtained at $30 \%$ when the cement is replaced with B.A 2 . 
[3] Comparing the results of the two trails, the results obtained by replacing cement with B.A.2 are better.

[4] Hence it can be concluded that B.A.2 is most preferable than B.A.1 as cement replacement material, and hence S.C.B.A is a good pozzolanic material.

\section{References}

[1] R.Srinivasan, K. Sathiya, Experimental Study on Bagasse Ash in Concreter, International Journal for Service Learning in Engineering, 2010, Vol. 5,No. 2, pp. 60-66,ISSN 1555-9033.

[2] Sumrerng Rukzon, Prinya chinda prasirt, Utilization of Bagasse Ash in High Strength Concrete, Elsevier LTD, 2011, Materials and Design 34 (2012) 45-50

[3] G.C.Cordeiro, R.D. Toledo filho, E.M.R. Fairbrain, Ultrafine Sugarcane Bagasse Ash: High Potential Pozzolanic Material for Tropical Countries, Ibracon Structures and Materials Journal, volume 3, p. 50-67, ISSN 1983-4195, 2010.

[4] N.B. Singh, V.D. Singh, S. Raj. Hydration of Bagasse Ash-Blended Portland Cement, Cement and Concrete Research, Vol.30, No.9, PP.1485-1488, 2000.

[5] K. Ganesan, K. Rajagopal, and K. Thangavel. Evaluation of Bagasse Ash as Supplementary Cementitious Material. Cement and Concrete Composites, vol.29, No.6, pp.515-524, 2007

[6] Abdolkarim Abbasi, Amin Zargar. Using Bagasse Ash in Concrete as Pozzolan. Middle-East Journal of Scientific Research 13(6), 716-719, 2013, ISSN. 1990-9233. 